\title{
Peran United Nations Human Rights Council (UNHRC) dalam Menangani Diskriminasi Terhadap Zainichi Koreans di Jepang
}

\author{
Fildza Nabila Anandhini \\ Departemen Hubungan InternasionalFISIP Universitas Hasanuddin, Indonesia; fildzanbl@ gmail.com
}

| submit:20-11-2020 | accept: 25-01-2021 | publish: 31-01-2021

\author{
Keywords \\ Minority Rights; Role of \\ International Organization; \\ UNHRC; zainichi Koreans
}

\section{Kata Kunci}

hak-hak minoritas, peran

Organisasi Internasional,

UNHRC, zainichi Koreans

\begin{abstract}
This research discusses the role of The United Nations Human Rights Council (UNHRC) in overcoming the problem of discrimination against "zainichi Koreans" in Japan. This type of research is descriptive with research problem "how is the role of UNHRC in overcoming the problem of discrimination against zainichi Koreans in Japan?" The researcher uses the theory of international organizations and the concept of minority rights as supporting concepts that explain the issue of minorities human rights. The data collection technique used was literature review, in the form of books, online media, and related documents. The study finds that UNHRC as an international organization has three roles in overcoming the problems of zainichi Koreans in Japan, namely initiator, facilitator, and mediator. As an initiator, UNHRC encourages law enforcement in protecting the zainichi Koreans in Japan. Meanwhile, as a facilitator, UNHRC holds forum to facilitate state and non-state actors to collaborate. And finally, as the mediator, UNHRC becomes an intermediary in resolving problems between Japan and South Korea.
\end{abstract}

\section{ABSTRAK}

Penelitian ini membahas tentang peran The United Nations Human Rights Council (UNHRC) dalam mengatasi perma salahan diskriminasi terhadap zainichi Koreans di Jepang. Jenis penelitian ini adalah deskriptif dengan rumusan masalah "bagaimana peran UNHRC dalam mengatasi perma sa lahan diskrimina si terha dap zainichi Koreans di Jepang?" Pen eliti menggunakan teori organisasi internasional dan konsep minority rights sebagaikonsep pendukung yang menjela skan mengenai ma salah hak -hak terhadap minoritas. Teknik pengumpulan data yang digunakan adalah telaah kepustakaan, berupa buku, media online, maupun dokumen terka it . Hasil penelitian menunjukkan bahwa UNHRC sebagai organisasi interna sionalyang bergerak dalam bidang hak a sa si manusia memiliki tiga peran dalam mengatasi permasalahan zainichi Koreans di Jepang, yaitu inisiator, fasilitator, dan mediator. Sebagai inisiator artinya UNHRC mendorong penegakan hukum terhadap zainichi Koreans di Jepang. Sedangkan sebagai fasilitator artinya UNHRC menjadi wadah untuk memfasilitasi aktor-aktor negara maupun non-negara untuk melakukan kerjasama. Dan yang terakhir, peran mediator yaitu sebagai perantara dalam menyelesaikan masalah antara Jepang dan Korea Selatan. 


\section{PENDAHULUAN}

Secara harafiah, zainichi berarti 'tinggal di Jepang'. Meskipun istilah ini dapat digunak an untuk semua orang asing yang telah men etap di Jepang, kata zainichi lebih sering diasosiasikan dengan keturunan Korea di Jepang. Hal ini diperkuat dengan apa yang dikemukakan oleh Toshiyuki Tamamura, yakni zainichi didefinisikan sebagai warga negara Korea yang berpindah ke Jepang sebelum aneksasi, mereka yang menetap di Jepang setelah berakhirnya Perang Dunia II, dan orang yang berpindah ke Kepulauan Utama Jepang selama periode kolonial (Amanda, 2014).

Kehadiran minoritas Korea di Jepang berawal ketika terbentuknya Ganghwa Treaty antara Korea dan Jepang. Perjanjian itu dijadikan sebagai titik balik bentuk imperialisme Jepang terhadap Korea. Hingga di tahun 1910, Jepang menganeksasi Korea. Dampak yang ditimbulkan sejak aneksasi tersebut adalah seluruh beras di Korea dialokasikan ke Jepang, sehingga angka kemiskinan meningkat.

Oleh karena itu, untuk keluar dari angka kemiskinan, orang Korea melakukan migrasi ke Jepang untuk meningkatkan kualitas hidupnya. Di Jepang, para lelaki dipekerjakan sebagai buruh yang dibayar dengan upah yang murah, dan sebagian perempuan diberdayakan sebagai comfort women atau yang biasa dikenal dengan wanita penghibur di masa kolinialisme Jepang. Perpindahan penduduk Korea ke Jepang didukung oleh UndangUndang Mobilisisasi Nasional 1938 yang dikeluarkan oleh Jepang untuk memobilisasi penduduk Korea untuk mendukung Jepang dalam Perang Dunia II (Pauer, 1999). Hal ini merupakan faktor pendorong bagi orang Korea melakukan migrasi ke Jepang. Namun setelah kekalahan Jepang terhadap Sekutu pada tahu n 1945, mereka diberikan pilihan untuk kembali ke Korea atau tetap berada di Jepang. Sekitar 650,000 orang memilih tinggal di Jepang (Kumpis, 2015). Akhirnya terbentuklah minoritas Korea di Jepang dan mereka disebut dengan generasi pertama zainichi Koreans.
Pasca tahun 1945, berbagai tindakan diskriminatif telah diberlakukan oleh Jepang, baik terhadap gaijin (orang asing secara umum), termasuk zainichi Koreans. Tindakan diskriminatif yang pertama adalah pemberlakuan peraturan terhadap orang a sing yang datang ke Jepang, yaitu Alien Registration Law 1952. Peraturan ini diberlakukan untuk semua orang asing, dimana peraturan ini merupakan simbol diskriminasi yang paling nyata yang pernah dialami oleh seluruh gaijin termasuk zaincihi Koreans sendiri. Aturan dalam Alien Registration Law ini antara lain, seluruh gaijin harus melakukan pengambilan sidik jari yang memiliki makna simbolik bahwa semua warga asing berpotensi untuk melakukan tindak kriminal (Tsu tsui K, 2008).

Sementara itu, tindakan diskriminatif khusus zainichi Koreans antara lain berupa dikecualikannya minoritas Korea dalam skema pensiun nasional negara sehingga zainichi Koreans tidak berhak mendapatkan skema pensiun nasional, dan hal tersebut telah melanggar pasal 5(e)(iv) dari International Convention of the Eliminaton of All Forms of Racial Discrimination (ICERD) (Lawyers Association of Zainichi Koreans, 2014). Pengecualian minoritas Korea ini meru pakan sebuah diskriminasi rasial. Melalui konvensi ICERD, Jepang dituntut untuk memperbaiki kebijakan mereka dalam skema pensiun nasional terhadap zainichi Koreans. Aturan ini didukung pula oleh penghapusan kewarganegaraan dari Undang-Undang Pensiun Nasional pada tahun 1982 yang dikombinasikan dengan usia dan persyaratan tempat tinggal yang diperkenalkan oleh amandemen tersebut. Di tahun 1986, sejumlah etnis minoritas yang telah menetap di Jepang sejak Perang Dunia Kedua, seperti orang China dan zainichi Koreans tid ak memenuhi syarat untuk mendapatkan manfaat pensiun di bawah skema pensiun nasional yang diatur oleh pemerintah Jepang (Committee on the Elimination of Racial Discrimination, 2014).

Tindakan diskriminatif lainnya adalah pengecualian penduduk dalam pekerjaan. 
Fenomenanya dalam pekerjaan publik, para kelompok minoritas seperti zainichi Koreans tidak dapat mendapatkan promosi untuk mendapatkan posisi manajerial. Situasi ini membatasi peluang seseorang untuk mendapatkan promosi, dimana semestinya hal tersebut merupakan hak mereka. Selain itu tindakan diskriminatif terbesar yang dilakukan oleh pemerintah Jepang adalah fenomena yang terjadi di wilayah di distrik Utoro, Kyoto. Pemerintah Jepang selama Perang Dunia Kedua menempatkan zainichi Koreans di Utoro untuk membangun bandara militer. Namun, ketika perang berakhir, proyek pembangunan ini ditinggalkan dan orang Korea yang bekerja di sana dilupakan dan ditinggalkan di tanah itu tanpa pekerjaan, sumber daya, maupun perlindungan atau status.

Realitanya, kondisi sanitasi di Distrik Utoro menyedihkan, pasalnya sejumlah besar keluarga tidak memiliki air yang mengalir, kota di sana tidak memiliki saluran untuk mengevakuasi air, yang sering memicu banjir. Saluran pembuangan air dalam kondisi terbuka yang levelnya sering naik karena kanal tetangga yang dikelola oleh kota Uji sering menyebabkan refluks ke saluran pembuangan Utoro. Infrastruktur dasar yang ada dibangun oleh penduduk sedangkan otoritas publik tidak pernah datang ke daerah ini. Penduduk melihat kurangnya infrastruktur dasar ini sebagai pelanggaran hak karena mereka yang bekerja telah membayar pajak penghasilan mereka.

Di bidang pendidikan, zainichi Koreans telah membangun sendiri sejumlah sekolah Korea, yang berfungsi melestarikan identitas nasional mereka. Sehingga dalam sekolah Korea ini, mereka mengajarkan sejarah-sejarah mengenai tanah air mereka. Di tahun 2010, pemerintah Jepang memperkenalkan Program Pengabaian Biaya Pendidikan yang akan membebaskan biaya sekolah untuk pendidikan sekolah menengah. Direncanakan untuk memasukkan tidak hanya sekolah negeri d an swasta Jepang, tetapi juga sekolah asing di Jepang yang terakreditasi sebagai 'sekolah lain-lain' di bawah Undang-Undang Pendidikan Sekolah. Ini adalah kesempatan pertama bagi semua sekolah Korea yang diakreditasi sebagai 'sekolah lain-lain' untuk diberikan subsidi oleh pemerintah pusat Jepang.

Namun, pemerintah memulai program tanpa menerapkannya ke sekolah Korea, karena penculikan warga Jepang pada 1970-an dan 1980-an oleh DPRK. Ini sama dengan menggunakan anak-anak Korea sebagai pion politik antara Tokyo dan Pyongyang.

Sekolah-sekolah Korea ini kurang mendapatkan pengakuan dari pihak berwenang Jepang, serta tidak menerima dukungan keuangan dari pemerintah Jepang. Karena Jepang memberlakukan sanksi ekonomi terhadap Korea Utara akibat penculikan warga negara Jepang dan program nuklirnya. Perlu diketahui bahwa sekolah Korea didukung secara finansial oleh Korea utara dan Asosiasi Umum Penduduk Korea proPyongyang di Jepang (Chongryon). Menurut pemeriksaan pemerintah Jepang, sekolahsekolah tersebut tidak sesuai dengan salah satu kriteria sekolah yang diberikan subsidi.

Masalah diskriminasi lainnya adalah terkait perlakukan terhadap perempuan minoritas Korea di Jepang, yaitu masalah comfort women. Kasus ini merupakan sistem perbudakan seksual wanita Korea yang dilakukan oleh militer Jepang selama Perang Dunia Kedua. Hubungan dari comfort women dengan zainichi Koreans adalah, ketika orang Korea melakukan migrasi ke Jepang, para lelaki dipekerjakan sebagai genkai rodusha atau pekerja marjinal di bidang industri, seperti pertambangan. Sedangkan kaum perempuan dijadikan sebagai jugun ianfu atau yang dikenal dengan comfort women. Dalam sehari, para korban ini mengalami pemerkosaan 10-50 kali perharinya (Yoshimi Y, 2000).

Mereka menderita berbagai macam penyakit, seperti kelaparan, penganiayaan fisik, penyiksaan, paksaan aborsi, dan sekitar $75 \%$ diperkirakan telah meninggal akibat hal 
tersebut (Brouwer, 2005). Jumlah korban d ari comfort women ini diperkirakan antara 40.000 dan 300.000. Menurut survey yang dilakukan oleh Center for War/Women's Rights, dari $30 \%$ para comfort women yang berasal dari Korea ini telah melahirkan anak, dimana $20 \%$ dari anak-anak tersebut diadopsikan.

Sejauh ini tidak ada data yang pasti mengenai bagaimana kehidupan anak-anak itu, pakah mereka mendapatkan tindakan diskriminatif atau tidak dalam kehidupan mereka. Hal ini disebabkan telah terjadi asimilasi kewarganegaraan. Dari beberapa tindakan diskriminatif yang telah penulis paparkan, terdapat berbagai tindakan yang sudah tidak dirasakan oleh zainichi Koreans turunan generasi ketiga maupun keempat di Jepang. Tindakan diskriminatif tersebut kebanyakan dirasakan oleh generasi pertama maupun kedua.

UNHRC melalui berbagai mandatnya telah memperhatikan isu zainichi Koreans di Jepang, antara lain mewajibkan setiap negara untuk berkomitmen menjaga hak asasi manusia, termasuk hak minoritas yang dilaporkan dalam Universal Periodic Review sekala berskala. Lalu, UNHRC juga mengutus special rapporteur dalam misi special procedure untuk mengirim sebuah tim untuk berkunjung ke negara yang memiliki persoalan mengenai pelaksanaan hak-hak warga negara dan berbagai aspek.

Namun masih ada perilaku diskriminatif seperti pengecualian penduduk dalam pekerjaan, pengecualian zainichi Koreans terhadap skema pensiun nasional, dan pengurangan biaya pendidikan terhadap sekolah Korea. Tetapi UNHRC telah berkontribusi besar dalam mendorong pemenuhan hak minoritas. Artikel ini akan menganalisa peran UNHRC dalam kasus ini.

\section{KERANGKA KONSEPTUAL}

Kerangka konseptual yang digunakan oleh penulis untu menganalisis peran UNHRC dalam menangani masalah diskriminasi terhadap zainichi Koreans di Jepang adalah konsep peran organisasi internasional dan minority rights.

\section{Konsep Peran Organisasi Internasional}

Organisasi internasional merupakan salah satu subyek hukum internasional yang mendorong negara-negara untuk melakukan kerjasama internasional. Organisasi Internasional send iri merupakan organisasi yang dibentuk beberapa negara dengan persetujuan antara anggotany a serta memiliki sistem yang tetap pada tugasnya, yaitu untuk mencapai tujuan bersama dengan cara mengadakan kerja sama antar negara anggotanya (Virally M, 2007).

Organisasi internasional adalah aktor penting dalam sebuah politik internasional, karena memiliki kekuatan dalam mediasi, penyelesaian sengketa, menjaga perdamaian, menerapkan sanksi, dan lain sebagainya. Organisasi internasional juga membantu dalam mengelola berbagai isu menjadi perhatian internasional, dari segala aspek mulai dari kesehatan global hingga kebijakan moneter di seluruh dunia (Abbot \& Snidal, 1998).

Organisasi Internasional memiliki fokus terhadap isu yang menjadi tujuan didirikannya organisasi tersebut. UNHCR adalah organisasi internasional yang bergerak di bidang hak asasi manusia memiliki struktur organisasi yang formal yang bertujuan untuk mendorong adanya kerjasama internasional dari negaranegara.

Organisasi Internasional memiliki tiga jenis peran, yaitu peran sebagai inisiator, fasilitator, dan mediator (Perwita, et. al, 2005). Sebagai inisiator, organisasi internasional dapat memulai langkah-langkah penyelesaian masalah; sebagai fasilitator, organisasi internasional mengupayakan kerjas ama; dan sebagai mediator, organisasi internasional melakukan upaya penyelesaian atas kasus pelanggaran HAM.

\section{Konsep Minority Rights}

Konsep minority rights intinya menyebutkan bahwa kelompok minoritas memiliki hak yang sama dengan kelompok mayoritas. Yang membedakan antara kelompok minoritas 
adalah budaya, suku, ras, dan bahasa sehingga seharusnya kedua kelompok ini (mayoritas dan minoritas) memiliki hak individu yang sama. Menurut definisi yang ditawarkan oleh Francesco Capotorti, Special Rappourteur of the United Nations Sub-Commission on Prevention of Discrimination and Protection of Minorities, minoritas adalah:

Sebuah kelompok yang secara numerik lebih rendah dari penduduk lainnya di suatu negara, dalam posisi non-dominan, yang anggotanya sebagai warga di negara tersebut - memiliki karakteristik etnis, agama atau bahasa yang berbeda dari populasi lainnya dan menunjukkan, jika hanya secara implisit, rasa solidaritas, diarahkan untuk melestarikan budaya, tradisi, agama atau bahasa mereka.

Jika ditinjau dari segi historisnya, gagasan minority rights telah ada sejak sistem kekaisaran Ottoman, memungkinkan tingkat otonomi budaya dan agama untuk komunitas agama non-Muslim, seperti Kristen Ortodoks, Armenia, Yahudi dan lain- lain. Diikuti dengan revolusi Prancis dan Amerika pada akhir abad ke-18 yang menyatakan kebebasan beragama sebagai hak fundamental, meskipu n keduanya tidak secara langsung membahas masalah perlindungan minoritas yang lebih luas. Kongres Wina tahun 1815 juga mengakui hak-hak minoritas sampai batas tertentu, seperti halnya Perjanjian 1878 di Berlin, yang mengakui hak-hak khusus untuk komunitas keagamaan Mount Athos (United Nations, 2012).

Sementara itu banyak yang berpendapat bahwa isu kelompok minoritas lebih baik ditangani melalui penghormatan terhadap hakhak asasi manusia. Kemudian dibuatlah berbagai perjanjian yang membahas mengenai minoritas untuk melindungi kelompokkelompok tertentu. Seperti pada tah un 1947, Sub-Commision on Prevention of Discrimination and Protection of Minorities dibentuk oleh Komisi Hak Asasi Manusia untuk mengkaji studi mengenai minoritas (United Nations, 2012)

Perlindungan ini penting karena sepanjang sejarah negara-bangsa modern, pemerintah memiliki kecenderungan untuk memandang minoritas, terutama minoritas yang sadar diri secara politik, sebagai ancaman potensial terhadap kesatuan politik atau integritas teritorial negara-negara tempat mereka tinggal. Ketika para elit penguasa menghadapi ancaman seperti itu, mereka cenderung bereaksi, antara lain, dengan mencoba menahan ancaman yang dirasakan dengan menghilangkan atau mengurangi perbedaan antara mayoritas dan minoritas. Pendekatan ini mungkin memerlukan kebijakan asimilasi, pemaksaan atau pemaksaan, atau tindakan yang lebih drastis, seperti pertukaran penduduk, pembersihan etnis, dan bahkan genosida (Esman, 1995).

Akhirnya pada tahun 1992, Majelis Umum PBB mengadopsi sebuah deklarasi yang bernama the United Nations Minorities Declaration 1992, dimana deklarasi ini dijadikan sebagai sumber utama dari minority rights. Poin-poin penting dari dokumen ini adalah sebagai berikut.

1. Perlindungan oleh negara dari keberadaan mereka dan identitas nasional atau etn is, budaya, agama dan bahasa (pasal 1);

2. Hak untuk menikmati budaya mereka sendiri, untuk mengaku dan menjalank an agama mereka sendiri, dan untuk menggunakan bahasa mereka sendiri secara pribadi dan di depan umum (pasal $2(1)$;

3. Hak untuk berpartisipasi secara efektif dalam budaya, agama, sosial, ekonomi, dan kehidupan publik (pasal 2 (2));

4. Hak untuk berpartisipasi secara efektif dalam keputusan yang memengaruhi mereka di tingkat nasional dan regional (pasal 2 (3));

5. Hak untuk membentuk dan mempertahankan asosiasi mereka send iri (pasal 2 (4));

6. Hak untuk membangun dan memelih ara kontak damai dengan anggota kelompok mereka yang lain dan dengan orang-orang yang termasuk kelompok minoritas lainnya, baik di dalam negara mereka 
sendiri maupun lintas batas Negara (pasal

2 (5)); dan

7. Kebebasan untuk menggunakan hak-hak mereka, secara individu maupun dalam komunitas dengan anggota lain dari kelompok mereka, tanpa diskriminasi (pasal 3) (United Nations, 2010)

Berdasarkan deklarasi tersebut, negaranegara harus melindungi hak-hak kelompok minoritas dengan mengambil langkah-langkah untuk memastikan bahwa mereka dapat melaksanakan sepenuhnya dan secara efektif semua hak asasi manusia dan kebebasan mendasar mereka tanpa diskriminasi dan kesetaran penuh di hadapan hukum, memberikan kesempatan yang memadai untuk mempelajari bahasa ibu mereka, perlunya bekerjasama dengan negara-negara lain pada pertanyaan yang berkaitan dengan minoritas, termasuk bertukar informasi dan pengalaman, untuk mempromoskan saling pengertian dan kepercayaan.

Dalam kerangka hukum internasional ini, beberapa tindakan diskriminatif yang dilakukan oleh pemerintah Jepang terhadap zainichi Koreans telah mengundang reaksi dari masyarakat internasional, termasuk UNHRC. Tindakan diskriminatif itu antara lain, selama ini zainichi Koreans yang telah menetap di Jepang semenjak 1945 tidak memiliki ruang bebas untuk bergerak dalam aspek sosial, ekonomi, dan politik. Mereka tidak memiliki kebebasan dalam menggunakan bahasa Korea dalam percakapan sehari-hari, maupun memelihara hubungan baik dengan sesama etnis di lintas negaranya karena dianggap mendoktrin ideologi asli dari asal negara mereka. Sampai saat ini, zainichi Koreans sebagai salah satu minoritas terbesar di Jepang belum diakui secara resmi oleh pemerintah Jepang sehingga diskriminasi pun kerap terjadi. Dalam hal ini, pemenuhan minority rights diperlukan untuk melindungi keberadaan etnis, budaya dan bahasa mereka. Dan tentunya menjamin mereka untuk memiliki ruang bergerak yang bebas.
Dalam upaya memenuhi hak-hak minoritas tersebut, peran dari asosiasi etnis dan NGO lokal tidaklah cukup. Perlu adanya aktor organisasi internasional yang memiliki peran dalam memfasilitasi, menginisiasi dan memediasi permasalahan diskriminasi tersebut. Dalam hal ini UNHRC sebagai organisasi internasional memiliki tugas dalam menjamin pemenuhan hak-hak minoritas dengan mengambil berbagai tindakan in siatif sebagai langkah untuk menyelesaikan masalah.

\section{METODE RISET}

Penelitian ini adalah penelitian kualitatif, dengan tujuan menjelaskan peran dari United Nations Human Rights Committee (UNHRC) dalam menangani diskriminasi terhadap zainichi Koreans di Jepang. Tipe kualitatif dalam penelitian ilmu Hubungan Internasional mempelajari fenomena dan aktor serta untuk memahami proses dan fenomena yang terjadi di dunia internasional (Bakry, 2016).

Oleh karena itu, melalui penelitian ini penulis memaparkan bagaimana fenomena tindakan diskriminatif yang dilakukan terhadap zainichi Koreans di Jepang, lalu menjelaskan aktor, yaitu UNHRC, dalam mengatasi tindakan tersebut dan bagaimana prosesnya.

Teknik pengumpulan data yang digun akan yaitu telaah pustaka (library research). Telaah pustaka merupakan metode pengumpulan datadata terkait yang berasal dari buku, jurnal, dokumen, laporan, artikel, atau surat kabar, baik daring maupun luring. Penulis menggunakan metode penulisan deduktif, yaitu menggambarkan permasalahan secara umum dan kemudian menarik kesimpulan.

\section{HASIL DAN PEMBAHASAN}

Peran UNHRC Dalam Menangani Masalah Diskriminasi Terhadap Zainichi Koreans di Jepang

Pada 30 Juni 2016, sekitar 400.000 warga Korea tinggal di Jepang dengan status special permanent resident (Ishkida, 2005). Namun, masalah diskriminasi terhadap zainichi 
Koreans di Jepang sangat memprihatinkan. Keadaan ini mengarah kepada penindasan terhadap hak-hak minoritas. Dengan demikian, peran organisasi dan keberadaan UNHRC diperlukan, untuk memberikan dukungan untuk menjamin dan melindungi hak-hak warga minoritas.

Faktanya, Jepang telah meratifikasi berbagai konvensi terkait HAM, seperti International Covenant on Civil and Political Rights, International Covenant on Economic, Social and Cultural Rights, the Convention against Torture and Other Cruel, Inhuman or Degrading Treatment or Punishment, the Convention on the Elimination of All Forms of Discrimination against Women, the Convention on the Rights of the Child and the International Convention on the Elimination of All Forms of Racial Discrimination. Akan tetapi masih ada sejumlah pelanggaran yang dilakukan, misalnya, pemerintah Jepang masih menyangkal bahwa penduduk Korea yang telah menetap di Jepang adalah etnis minoritas nasional Jepang, sebagaimana didefinisikan dalam Pasal 27 ICCPR atau deklarasi PBB tentang Hak-Hak Minoritas (Human Rights Committee, 2014).

Etnis minoritas yang diakui oleh Jepang adalah etnis minoritas Ainu. Oleh karena itu, untuk masalah diskriminasi yang terjadi di Jepang, termasuk kasus yang dihadapi minoritas Korea, Komisi Hak Asasi Manusia (HAM) atau UNHCR memberikan mandat pertama kepada Special Rapporteur, yaitu Doudou Diène, di tahun 2005 dan disusul oleh Jorge Bustamante di tahun 2011, untuk melakukan observasi lebih lanjut untuk melakukan investigasi dan pelaporan mengenai pelanggaran terhadap hak-hak minoritas.

Selain itu, special rappourteur juga melakukan upaya lain dalam mengumpulkan informasi. Di tahun 2005, ketika UNHRC membuat mandat untuk melakukan special procedure, special rappourteur mengumpulkan informasi dengan berbagai cara, antara lain sebagai berikut:
1. Doudou Diène dan timmnya mengadakan pertemuan dengan berbagai stakeholders untuk mendengar kepentingan mereka, tentang adanya diskriminasi rasial dan xenophobia di Jepang. Dalam konteks ini, mereka bertemu dengan Wakil Menteri Luar Negeri Jepang kala itu, perwakilan dari berbagai kementerian, hakim serta perwakilan dari pemerintah daerah Osaka, Kyoto, Tokyo dan Sapporo, dan sejumlah komunitas, seperti Sekolah Korea di Kyoto dan komunitas Korea Utoro di Kota Uji di Kyoto.

2. Melakukan kunjungan ke Distrik Utoro, tempat komunitas Korea ditempatk an di sebidang tanah selama Perang Dunia Kedua untuk membangun bandara militer, lalu proyek itu diabaikan sehingga komunitas Koreapun hidup dengan menderita selama 60 tahun di sana.

3. Melakukan kunjungan ke Sekolah Menengah Korea di Perfektur Kyoto, untuk mendapatkan informasi, dimana sekolah-sekolah Korea tidak menerima dukungan keuangan dari pemerintah dan siswa Korea tidak memiliki kelayakan untuk mengikuti ujian masuk Universitas Jepang (Commision on Human Rights, 2006).

Setelah mengumpulkan dan mengobservasi keadaan di Jepang, Pelapor Khusus menyimpulkan terdapat bahwa terdapat diskriminasi rasial dan xenophobia di Jepang, yang mana mempengaruhi tiga lingkaran kelompok, dan salah satunya adalah zaincihi Koreans. Hasil observasi mereka antara lain, terjadi tindakan diskriminatif dalam berbagai aspek, seperti sifat sosial dan ekonomi, dimana kaum minoritas ini hidup dalam situasi termarginalisasi dan mengalami kerentanan ekonomi dan sosial, di bidang pekerjaan, perumahan, dan pendidikan.

Pada tahun 2010, UNHRC memberikan mandat untuk melakukan Special Procedure, yaitu dengan Pelapor Khusus yang dipimpin oleh Jorge A. Bustamante. Bustamante 
menyatakan bahwa selama melakukan observasi selama 9 hari di Jepang, masih terdapat banyak tindakan rasisme, diskriminasi, eksploitasi dan lain-lainnnya Dalam laporannya, Bustamante menjelask an mengenai masalah pendidikan yang pernah dilaporkan pada tahun 2005 oleh Pelapor Khusus sebelumnya. Seperti di tahun 2003, Pemerintah Jepang memberikan akses ujian masuk ke universitas di Jepang untuk lu lus an sekolah asing, namun bagi mereka yang berasal dari Repubilk Rakyat Demokratik Korea dikecualikan. Hal ini didukung masalah politik antara Korea Selatan dan Jepang, akibatnya para siswa ini merasa didiskriminasi karena akses mereka untuk memasuki universitas di Jepang tidak dijamin oleh pemerintah. Selain itu juga bermunculan tulisan "Japanese Only" di berbagai toko atau tempat makan, yang menyasar etnis-etnis minoritas seperti minoritas Korea Office of United Nations of High Commissioner of Human Rights, 2010).

Upaya UNHRC tidak berhenti hanya pada kegiatan Special Procedure untuk memaksimalkan peran UNHRC sebagai organisasi internasional. UNHRC juga mencoba mendorong Jepang melalui berbagai cara, seperti kewajiban pemerintah Jepang untuk membuat laporan observasi dengan berbagai badan perjanjian yang telah diratifikasi oleh Jepang. Hal ini dilakukan untuk memantau pemerintah Jepang dalam mempromosikan HAM, termasuk hak minoritas di negaranya.

Selain itu terdapat The Universal Periodic Review dimana UPR merupakan sebuah forum yang mengobservasi atau memantau kemajuan isu HAM setiap 4,5 tahun sekali. Isu dari minoritas Korea di Jepang, menjadi isu internasional, karena berkaitan dengan ketidakselarasan antara situasi hak-hak minoritas di Jepang dengan apa yang sudah dirancang dalam Deklarasi Hak-Hak Minoritas. UPR ini mulai berfungsi pada tahun 2008, dimana setiap negara akan menjela skan permasalahan mengenai HAM, termasuk hak minoritas di negaranya, dan bagaimana mereka menangani masalah tersebut. Jepang telah mengikuti tiga kali UPR, yaitu di tahun 2008, 2012 dan 2017.

Walaupun minoritas Korea di Jepang belum dimasukkan sebagai etnis nasional di Jepang, terlihat dari laporan observasi maupun Universal Periodic Review bahwa permasalahan diskriminasi terhadap minoritas Korea selalu dibahas, baik diaspek sosial, ekonomi, sejarah, maupun pendidikan. Dan terdapat berbagai rekomendasi yang diberik an baik dari PBB sendiri, maupun negara lain.

Selanjutnya, penulis akan menganalisis peran dari UNHRC. Organisasi Internasional memiliki 3 peran, yakni inisiator, fasilitator dan mediator (Perwita, et. al, 2005).

\section{Peran UNHRC Sebagai Inisiator}

Berdasarkan tugas dari UNHRC yaitu untuk melindungi hak-hak manusia, UNHRC telah mengambil peran, antara lain sebagai berikut.

Pertama, UNHRC mendorong penegak an hukum atau advokasi, yang menjadi tantangan dalam menegakkan hak-hak minoritas di Jepang. Berkat bantuan dari jaringan nasion al LSM dan individu yang melaporkan masalah hate-speech, termasuk masalah sekolah Korea di Kyoto, kasus ini akhirnya dibawa ke forum internasional di PBB (Jinshu Sabetsu Teppai, 2017). Dalam sesi badan perjanjian UNHRC untuk meninjau laporan observasi berkala pemerintah Jepang tentang pelaksanaan konvensi hak asasi manusia pada tahun 2014 , kasus-kasus hate-speech pada sekolah Korea di Kyoto tersebut dibahas. Dalam sesi itu ditayangkan video yang mendokumentasikan demonstrasi pidato kebencian yang sangat meremehkan. Adanya peningkatan perhatian media massa atas kasus ini dan dukungan dari UNHRC, PBB pun mengeluarkan rekomendasi tegas bagi Jepang untuk menyelesaikan masalah hate-speech itu pada musim panas 2014 (Hatano, 2019).

Kasus ini menjadi titik balik dalam sikap Jepang terhadap isu ini. Jepang pun memberlakukan UU anti kebencian pertama di negara tersebut, yaitu Act on the Promotion of Efforts to Eliminate Unfair Discriminatory 
Speech and Behavior Agains Persons Orgiginating from Outside Japan atau Hate Speech Elimination Act. Undang-undang ini diberlakukan untuk menumbuhkan kesadaran di kalangan masyarakat umum mengenai hakhak yang dimiliki manusia (Hatano, 2019).

Kedua, UNHRC mendorong diakuinya status zainichi Koreans sebagai etnis minoritas. Mereka telah diberi status special permanent resident sejak tahun 1991, namu n pemerintah Jepang terus-menerus menyangkal bahwa penduduk Korea adalah minoritas nasional atau etnis sebagaimana didefinisikan dalam Pasal 27 ICCPR atau Deklarasi PBB tentang Hak-Hak Minoritas. Dalam Laporan Jangka Menengah pada Januari 2017, pemerintah Jepang hanya melaporkan kebijakan yang terkait dengan masyarakat adat Ainu sehubungan dengan etnis minoritas, dan tidak menyebut penduduk Korea di Jepang sebagai minoritas (The Government of Japan, 2017).

Oleh karena itu, UNHRC terus memberikan rekomendasi dan mengangkat isu zainichi Koreans, agar mereka mendapatkan hak hukum yang komprehensif.

Ketiga, UNHCR membantu mengangkat isu masalah zainichi Koreans ke kancah internasional, karena efek dari media sosial sangat efektif dalam menyebarluaskan berita mengenai keadaan mereka. Contohnya, pada peringatan 60 tahun berakhirnya Perang Dunia II PBB memberikan mandat kepada Pelapor Khusus untuk mengunjungi Utoro pada tahun 2005. Tugas Pelapor Khusus ini adalah melakukan observasi dan pengumpulan data . Dalam melakukan tugasnya, ia didukung oleh jaringan TV Korea Selatan yang merencanakan acara khusus Utoro, serta beberapa media terkemuka, termasuk mingguan progresif Hankyoreh 21. Mediamedia itu menayangkan berbagai artikel mengenai kasus ini disertai penggalangan sumbangan untuk menyelamatkan desa Utoro.

Salah satu jaringan televisi menayangkan siaran langsung lima jam termasuk konser solidaritas pada 15 Agustus, peringatan berakhirnya perang (Mcnehill, 2005). Setelah itu banyak bantuan yang diberikan untuk para masyarakat minoritas Korea di Utoro yang terancam dievakuasi karena tanah yang mereka tempati telah dijual kepada sebuah perusahaan swasta. UNHRC dengan mandat yang diberikan oleh PBB mengunjungi Utoro, dan akhirnya masalah ini didengar oleh masyarakat internasional. Hasilnya, bantuan dari IGO maupun NGO pun berdatangan. Pada akhirnya di tahun 2018, minoritas Korea y ang ada di distrik Utoro telah dipindahkan ke sebuah lokasi perumahan.

\section{Peran UNHRC Sebagai Fasilitator}

UNHRC juga memiliki tugas untuk menciptakan kerjasama dengan pihak lain. Dengan demikian, UNHRC menjalankan perannya sebagai fasilitator untuk memfasilitasi berbagai non-state actors agar dapat bekerja sama dengan pemerintah Jepang. Antara lain, yang dilakukan UNHRC adalah memastikan penyampaian informasi sebaik mungkin, Human Rights Committee yang mengawasi penyelanggaraan ICCPR di setiap negara, serta mengundang organisasi nonpemerintah dan berbagai lembaga HAM nasional untuk memberikan laporan yang berisi informasi spesifik negara tersebut.

Dalam hal ini, Komite berhak untuk menentukan, pada tahap selanjutnya, apak ah pengarahan lain oleh organisasi nonpemerintah juga harus menjadi bagian dari pejabat Komite. Berbagai stakeholders, seperti Human Rights Now, Lawyers Association of Zainichi Koreans memberikan laporan beserta rekomendasi mereka. Hasil dari upaya ini, pemerintah Jepang pun mementingkan dialog dengan masyarakat sipil, termasuk LSM dan NGO untuk membahas mengenai isu tersebut dan untuk kepentingan Jepang send iri dalam menyusun laporan (Human Rights Council, 2017).

Laporan yang ada di lampiran disusun berdasarkan resolusi Dewan Hak Asasi Manusia 5/1 dan 16/21, dengan mempertimbangkan periodisitas dari tinjauan 
periodik universal. Ini adalah sebuah ringkasan pengajuan 37 pemangku kepentingan untuk meninjau Universal Periodic Review. Dari 37 pemangku kepentingan tersebut terdapat Lawyers Association of Zainichi Koreans (LAZAK), Mindan yakni Korean Residents Union di Jepang, yaitu NGO yang berlatar belakang zainichi Koreans. Antara lain yang disampaikan LAZAK dan Mindan adalah:

"MINDAN dan LAZAK prihatin bahwa
Pemerintah Jepang terus-menerus
menyangkal penduduk Korea sebagai
minoritas nasional atau etnis sebagaimana
didefinisikan dalam Pasal 27 ICCPR atau
Deklarasi PBB tentang Hak Minoritas. Selain
itu, tidak ada tindakan yang diambil untuk
menetapkan kondisi yang diperlukan untuk
perlindungan dan promosi identitas budaya
dan bahasa penduduk Korea," (Human
Rights Council, 2017).

NGO-NGO tersebut khawatir akan keberadaan zainichi Koreans yang sampai saat ini belum diakui sebagai etnis nasional, sesuatu yang seharusnya dilakukan Jepang bila mengikuti Deklarasi PBB mengenai hak-hak minoritas. Belum adanya pengakuan ini akan berdampak kepada perlakuan terhadap minoritas Korea di Jepang, antara lain minoritas Korea tidak memiliki ruang bebas untuk bergerak karena belum mendapatkan perlindungan secara hukum tentang keberadaan mereka. Oleh karena itu UNHRC menjalankan perannya sebagai fasilitator dalam mendukung minoritas Korea ini agar dijadikan sebagai etnis nasional, dengan memberikan wadah terhadap IGO, NGO d an pemerintah Jepang untuk membahas isu tersebut seperti yang sudah dipaparkan di atas.

\section{Peran UNHRC Sebagai Mediator}

Peran terakhir yang dilakukan UNHRC adalah menciptakan suatu penyelesaian yang efektif atas kasus pelanggaran kemanusiaan yang terjadi kepada minoritas Korea. Salah satu kasus terbesar adalah comfort women diman a Jepang (di masa perang) merupakan aktor yang telah melakukan tindakan kejahatan kemanusiaan tersebut. PBB secara proaktif membahas isu comfort women dan memberikan rekomendasi terhadap Jepang untuk melakukan semacam dialog atau membuat perjanjian dengan Korea Selatan. Jepang telah mengakui pertanggungjawabannya terhadap comfort women sejak tahun 1991 dan dibuatlah Asian Woman Fund, untuk memberikan bantuan berupa dana kepada korban.

Pada tahun 2014, UN Committee on the Elimination of Racial Discrimination, melalui ketuanya, Anastasia Crickley, telah memanggil Jepang untuk melakukan investigasi lebih lanjut mengenai kekerasan yang dilakukan terhadap comfort women. Tak hanya itu melalui UN Human Rights Commissioner, Navi Pillay, selalu memberikan dukungan terhadap comfort women agar mendapatkan keadilan. UNHRC dengan berbagai perjanjian internasional di bawahnya selalu menyerukan, Jepang dan Korea Selatan untuk menyelesaikan hal ini.

Lalu ditahun 2015, Pemerintah Jepang dan Pemerintah Korea mengadakan konsultasi intensif mengenai masalah ini, dan didapatkan kesepakatan untuk memberikan penyembuhan kepada kaum perempuan mantan comfort women tersebut (Governemnt of Japan, 2019). Pemerintah Jepang juga harus membayar senilai 200 juta won (\$172.000) per korban. Dengan perjanjian ini, kedua pemerintah mengkonfirmasikan bahwa masalah wanita penghibur akhirnya diselesaikan dan kedua pemerintah akan menahan diri untuk tidak saling menuduh atau mengkritik masalah ini dalam komunitas internasional, termasuk di PBB. Mr. Ban Ki Moon, selaku Sekertaris Jenderal dari PBB waktu itu berharap perjanjian ini dapat meningkatkan hubungan bilateral kedua negara (United Nations Secretary General, 2015).

Jika dilihat dari konsep organisasi internasional, UNHRC telah menjalankan mandatnya dalam mempromosikan hak-hak asasi manusia, terutama dalam memenuhi hakhak minoritas dalam sebuah negara. Kasus zainichi Koreans di Jepang merupakan salah satu bukti dari peran nyata UNHRC sebagai 
inisiator, fasilitator, maupun mediator dalam menangani masalah diskriminasi.

\section{KESIMPULAN}

Organisasi internasional memiliki fungsi sebagai mediator, inisiator, dan fasilitator dalam memecahkan permasalahan global. Melalui konsep organisasi internasional dan hak minoritas, tulisan ini menjawab permasalahan keterkaitan hubungan isu konseptual dari peran organisasi yaitu UNHRC dan hak minoritas dalam kasus zainichi Koreans. Konsep hak minoritas digunakan sebagai salah satu dasar bagi organisasi internasional untuk menjalankan misinya, dalam mengatasi permasalahan mengenai diskriminasi yang terjadi diseluru $\mathrm{h}$ dunia.

Sedangkan konsep organisasi internasion al digunakan sebagai alat analisis terhadap peran yang dilakukan UNHRC dalam menangani masalah diskriminasi di Jepang. Hasil pelaksanaan ketiga peran itu (mediator, inisiator, dan fasilitator) dapat terlihat dari semakin luasnya pemberitaan mengenai isu diskriminasi terhadap zainichi Koreans sehingga diketahui masyarakat internasion al. Selain itu telah terlihat beberapa kebijakan yang diimplementasikan oleh pemerintah Jepang, akibat dari teguran PBB dan UNHRC. Beberapa masalah telah terselesaikan seperti isu distrik Utoro, comfort women, dan hatespeech karena Jepang membuat sebuah kebijakan Hate Speech Elimination Act un tuk menangani kegiatan hate-speech terhadap zainichi Koreans.

Namun demikian, tindakan diskriminasi terhadap zainichi Koreans belum secara tuntas untuk ditangani. Hal ini karena keberadaan minoritas Korea di Jepang belum diakui sebagai identitas minoritas di Jepang, sehingga perilaku diskriminatif masih kerap terjadi. Oleh karena itu, kehadiran UNHRC masih diperlukan dalam menjalankan mandatnya sebagai inisiator, fasilitator dan mediator dalam permasalahan diskriminasi zainichi Koreans di Jepang.
Dengan demikian dapat ditarik kesimpulan bahwa UNHRC telah berperan sebagai, pertama, inisiator dalam menginisiasi penegakan hukum terhadap hak minoritas zainichi Koreans di Jepang, dengan menyuarakan kasus diskriminasi ini agar dibahas di forum internasional PBB. UNHRC juga menginisiasi LSM lokal untuk menyuarakan pendapat mereka. Hingga di tahun 2014, PBB mengeluarkan rekomend asi tegas bagi Jepang untuk memperbaiki masalah tersebut.

Kedua, UNHRC telah berperan sebagai fasilitator yang bertindak dalam memfasilitasi dialog antara pemerintah Jepang dengan nonstate actors lainnya, seperti IGO maupun NGO. Pandangan dari stakeholders ini ditampung dan dipertimbangkan oleh pemerintah Jepang dalam menyu su n laporan Universal Periodic Review yang dikirim ke UNHRC.

Ketiga, UNHRC telah berperan sebagai mediator yang dapat dilihat dari perannya dalam memediasi permasalahan comfort women antara Korea Selatan dan Jepang. Masalah ini merupakan masalah yang telah berlarut dan UNHRC menyerukan masalah ini untuk diselesaikan, dengan melakukan investigasi terhadap Jepang dan menyerukan dialog antara kedua negara. Hasilnya, di tahun 2015 terciptalah pemecahan masalah comfort women dalam konsultasi intensif yang telah dilakukan.

\section{DAFTAR PUSTAKA}

Abbot, K., \& Snidal, D. (1998). Why States Act through Formal International Organization. The Journal of Conflict Resolution, 3-32.

Amanda Clarissa Himawan (2014). Latar Belakang Perubahan Kebijakan Pemerintah Jepang terhadap Minoritas Korea (Zainichi Koreans). Jogjakarta. Universitas Gadjah Mada

Anak Agung Banyu Perwita, D. Y. (2005). Pengantar Ilmu Hubungan Internasional. Rosda. 
Bakry, U. S. (2016). Metode Penelitian Hubungan Internasional. Yogyakarta: Pustaka pelajar.

Bouwer. (2005) de Supranational Criminal Prosecution of Sexual Violence Case of The Japan Times 2000-2014. International Journal of AreaStudies.1,0

Commision on Human Rights. (2006). Racism, Racial Discrimination, Xenophobia and All Forms of Report of the Special Rapporteur on contemporary forms of racism, racial discrimination, xenophobia and related intolerance, Doudou Diène

United Nations. Committee on Elimination of Racial Discrimination. (2014). Concluding Observations on the combines seventh to ninth periodic reports of Japan. United Nations.

Governemnt of Japan. (2019). C Concluding Observations by the Committee on Enforced Disappearances (CED). GOJ.

Human Rights Council. (2011). Report of the Special Rapporteur on the human rights of migrants, Jorge Bustamante. United Nations.

Human Rights Council. (2017). Workin Group on the Universal Periodic Review.

Human Rights Council. (2017). Summary of Stakeholders's submission on Japan. United Nations.

Human Rights Committee. (2014). Concluding Observations on the sixth periodic report of Japan. United Nations.

Kumpis, A. (2015). Representations of Zainichi Koreans in Japanese Media: The Case of The Japan Times 20002014. International Journal of Area Studies.1,0

Lawyers Association of Zainichi Koreans. (2014). Discrimination Against Koreans in Japan: Japan's Violation of International Convention on the Elimination of All Forms of Racial Discrimination. Geneva LAZAK.

Office of the High Commissioner for Human Right. (2010). Minority Rights: International Standards and Guidance for Implementation. New York.

Pauer, E. (1999). Japan's War Economy. London:Routledge.

The Comfort Woman and The Asian Women's. (2007) Attempts at Legislation in the Japanese Diet.
Tsutsui K, S. (2008). Global Norms, Local Activism, andSocial Movement Outcames: Global Human Rights and Resident Koreans in Japan". Social Problems Vol. $55,391-418$.

United Nations. (2014). https://www.mofa.go.jp/files/00006 744.pdf. diakses pada 25 Mei, 2019, dari Ministry of Foreign Affairs of Japan: https://www.mofa.go.jp,

United Nations Secretary General. (2015). Statement attributable to the Spokesman for the Secretary-General on the Agreement between Japan and the Republic of Korea on issues related to 'comfort woman'. United Nations.

United Nations. (2010). Minority Rights: International Standards and Guidance for Implementation. New York: Office of the United Nations High Commissioner for Human Rights.

United Nations. (2012). Promoting and Protecting Minority Rights. Geneva, New York: United Nations High Commissioner for Human Rigths.

Virally M. (2007). Definition and Clasification of International Organization: A legal Approach. London.

Yoshimi Y. (2013) Comfort Women: Sexual Slavery in Japanese Military During World War II

\section{BIOGRAFI}

Fildza Nabila Anandhini merupakan alumni Departemen Ilmu Hubungan Internasional, Fakultas Ilmu Sosial dan Ilmu Politik, Universitas Hasanuddin yang memiliki ketertarikan terhadap dinamika kawasan Asia Timur, dan isu human rights terutama dala m aspek minority rights. 